\section{Modelling continuous data}

G ilbert Welch and colleagues I have written an interesting essay contrasting continuous and categorical approaches to modelling the relation between exposure and health effects. ${ }^{1}$ They suggest that assuming a continuous relation between exposure and outcome may produce misleading results and state that this assumption "is less the result of a considered decision than a practice born out of convention and convenience. The convention is that biologic relations ought to be smooth. ... The convenience is ... [in summarizing] the relation between multiple levels of exposure and the outcome in a parsimonious manner."

The authors have not mentioned one of the more compelling reasons for using a continuous relation in modelling: the ability to smooth out sampling variability among the discrete categories. The data they used for illustrative purposes are from population-based samples. As such, there will be sampling variability associated with each category, which is conventionally presented as $95 \%$ confidence intervals on the outcome in each category. The authors have completely ignored sampling variability; they have assumed that the observed outcomes are $100 \%$ precise. Had they included error bars in their graphs of outcome data, they would probably have observed substantial uncertainty about the point estimates in each of the categories and would have been less inclined to state, for example, that "[in Fig. 1] there is a slight increase in mortality between the moderate and high adherence categories [for men]."

A well-conducted regression analysis using continuous data will include model checking to confirm that the model captures the appropriate functional form (e.g., linear v. quadratic) and is not distorted by outliers. One must bear in mind, and not be fooled by, random fluctuations from category to category.

\section{Murray M. Finkelstein}

Department of Family and Community Medicine

Mt. Sinai Hospital

Toronto, Ont.

\section{Reference}

1. Welch HG, Schwartz LM, Woloshin S. The exaggerated relations between diet, body weight and mortality: the case for a categorical data approach [editorial]. CMA7 2005;172(7):891-5.

DOI:10.1503/cmaj.1050102

We received no response from Dr. Welch to our invitation to reply to this letter.

\section{Seasonal variation in birth weight}

$\mathrm{H}$ ope Weiler and colleagues noted that it was difficult to explain their observation that newborns with vitamin $\mathrm{D}$ deficiency were heavier and longer and had greater head circumferences than newborns with adequate vitamin. ${ }^{1}$ However, their findings are consistent with several studies examining the impact of season of birth on neonatal anthropometry. ${ }^{2}$ For example, our group found that birth weight, birth length and head circumference all fluctuated across the seasons, with peak values in children born during the winter and spring, when hypovitaminosis $\mathrm{D}$ is most prevalent. ${ }^{3}$

Vitamin D suppresses cell proliferation and promotes cell elimination via apoptosis in a variety of tissues. ${ }^{4}$ Thus, its absence in the prenatal period could lead to inappropriately high cell numbers, which could subsequently influence the size of the offspring. Evidence from animal experiments indicates that these mechanisms do have an impact on fetal growth. For example, the newborn offspring of normocalcemic rats de- prived of vitamin $\mathrm{D}$ were significantly heavier than those of control animals and there were subtle changes in the shape of their brains. ${ }^{5}$ Guinea pig fetuses exposed to low levels of vitamin D had expanded growth plates in their long bones. ${ }^{6}$ If similar mechanisms operated in humans, we would predict precisely what Weiler and colleagues have found: the newborns of mothers with hypovitaminosis D should be heavier (due to increased cell number) and longer (due to wider growth plates in the lower limb bones).

\section{John J. McGrath}

Thomas H. Burne

Darryl W. Eyles

Queensland Centre for Mental Health

Research

University of Queensland

St. Lucia, Australia

\section{References}

1. Weiler H, Fitzpatrick-Wong S, Veitch R, Kovacs $H$, Schellenberg J, McCloy U, et al. Vitamin D deficiency and whole-body and femur bone mass relative to weight in healthy newborns. CMA7 2005;172(6):757-61.

2. Wohlfahrt J, Melbye M, Christens P, Andersen AM, Hjalgrim H. Secular and seasonal variation of length and weight at birth. Lancet 1998;352 (9145):1990.

3. McGrath JJ, Keeping D, Saha S, Chant DC, Lieberman DE, O'Callaghan MJ. Seasonal fluctuations in birth weight and neonatal limb length; does prenatal vitamin D influence neonatal size and shape? Early Hum Dev 2005;81 (7):609-18.

4. DeLuca HF, Krisinger J, Darwish H. The vitamin D system: 1990. Kidney Int Suppl 1990;29. S2-8.

5. Eyles D, Brown J, Mackay-Sim A, McGrath J, Feron F. Vitamin D3 and brain development. Neuroscience 2003;118(3):641-53.

6. Rummens K, van Bree R, Van Herck E, Zaman Z, Bouillon R, Van Assche FA, et al. Vitamin D deficiency in guinea pigs: exacerbation of bone phenotype during pregnancy and disturbed fetal mineralization, with recovery by $1,25(\mathrm{OH}) 2 \mathrm{D} 3$ infusion or dietary calcium-phosphate supplementation. Calcif Tissue Int 2002;71(4):364-75.

DOI:10.1503/cmaj.1050100

\section{[Dr. Weiler responds:]}

Tohn McGrath and colleagues are correct that seasonality could be a factor contributing to the higher birth 
weight we observed among infants born with a vitamin $\mathrm{D}$ deficiency. ${ }^{1}$ Proving a relationship between maternal exposure to sunshine, infant vitamin D status and infant size at birth is difficult because of the high cost of analyzing circulating 25-hydroxyvitamin D levels in a large cohort, quantifying skin exposure to ultraviolet $\mathrm{B}$ light and endogenous synthesis of vitamin $\mathrm{D}$, and assessing the confounder, dietary vitamin D intake.

Other seasonally varying factors such as temperature are linked to size at birth. ${ }^{2}$ It is important to point out that the 299-g difference in birth weight between the infants with deficient and ad- equate vitamin D status in our study is 10 times greater than the weight difference that would be expected because of seasonal effects alone in industrialized countries. ${ }^{2}$ In the Winnipeg cohort, vitamin D status was highest in infants born in the summer (although season did not contribute to the regression analysis for bone mineral content in our study), but body weight did not follow the same pattern (Fig. 1).

It is possible that the infants born with vitamin $\mathrm{D}$ deficiency might have had a higher birth weight because of maternal exposure to sunshine in the first trimester. ${ }^{2}$ The spring-born infants $(n=14)$ tended to weigh the most (dif-
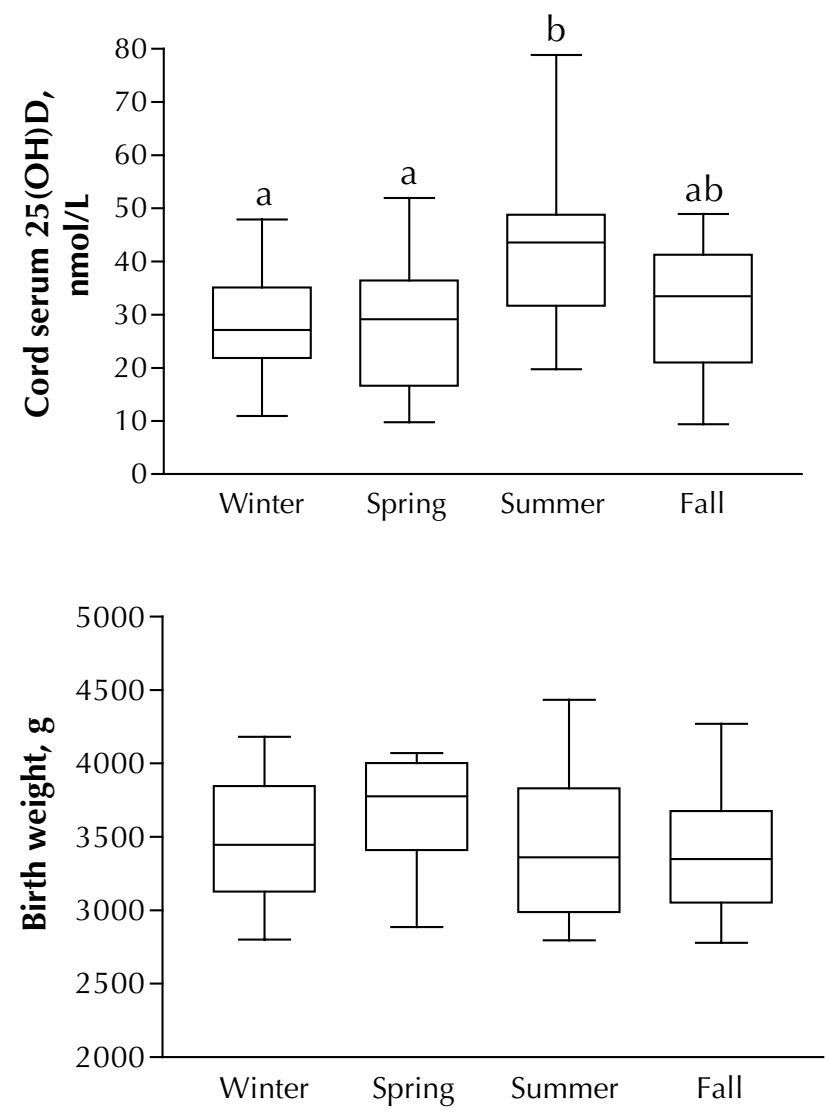

Fig. 1: Infant vitamin D status (above) and weight at birth (below) categorized by season. Seasons are defined as winter: January through March $(n=14)$; spring: April through June ( $n=14)$; summer: July through September $(n=12)$; fall: October through December $(n=10)$. Differences among groups were tested using ANOVA with Tukey's multiple comparison test. Bars with different letters indicate differences between groups $(p<0.05)$. (There were significant differences between the summer months and those in winter and spring. There were no significant differences between the fall months and the rest of the year.)

ference of $244 \mathrm{~g}, p=0.08, t$ test). These infants would have been conceived in the peak period of sunshine and warm temperatures in Winnipeg. Whether vitamin $\mathrm{D}$ status at the time of conception is behind these differences is unclear. In addition, melatonin should be included in future research on the relationships among seasonality, vitamin D, growth and bone mass. ${ }^{3}$

\section{Hope Weiler}

Department of Human Nutritional

Sciences

University of Manitoba

Winnipeg, Man.

\section{References}

1. Weiler H, Fitzpatrick-Wong S, Veitch R, Kovacs $H$, Schellenberg J, McCloy U, et al. Vitamin D deficiency and whole-body and femur bone mass relative to weight in healthy newborns. CMA7 2005;172(6):757-61.

2. Tustin K, Gross J, Hayne H. Maternal exposure to first-trimester sunshine is associated with increased birth weight in human infants. Dev Psychobiol 2004;45:221-30.

3. Cardinali DP, Ladizesky MG, Boggio V, Cutrera RA, Mautalen C. Melatonin effects on bone: experimental facts and clinical perspectives. $\mathcal{F}$ Pineal Res 2003;34:81-7

DOI:10.1503/cmaj.1050125

\section{Nonalcoholic fatty liver disease}

T eon Adams and associates ${ }^{1}$ rightly Lstate that obesity is associated with nonalcoholic fatty liver disease (NAFLD). In particular, visceral adiposity is highly correlated with NAFLD, whereas the correlation with subcutaneous obesity is weaker. ${ }^{2}$

Intra-abdominal fat delivers fatty acids directly into the portal vein, promoting insulin resistance. ${ }^{2}$ Patients with truncal obesity have very low levels of adiponectin and high levels of tumour necrosis factor- $\alpha$ (TNF- $\alpha){ }^{3}$ Secretion of TNF- $\alpha$ from adipose tissue is strongly associated with obesity-related insulin resistance, which suggests that TNF- $\alpha$ may function in a paracrine fashion in adipose tissue; in contrast, expression of adiponectin from adipose tissue is associated with higher degrees of insulin sensitivity and lower TNF- $\alpha$ expression. ${ }^{4}$ In addition, TNF- $\alpha$ has 